Research paper

\title{
Involvement of TLR6 in the induction of COX-2, PGE 2 and IL-10 in macrophages by lipids from virulent S2P and attenuated R1A Babesia bovis strains
}

\author{
G. Gimenez ${ }^{\mathrm{a}, *}$, M.L. Belaunzarán ${ }^{\mathrm{a}}$, K.G. Magalhães ${ }^{\mathrm{b}}$, C.V. Poncini ${ }^{\mathrm{a}}$, E.M. Lammel $^{\mathrm{a}}$, \\ S.M. González Cappa ${ }^{a}$, P.T. Bozza ${ }^{c}$, E.L.D. Isola ${ }^{a}$ \\ a Instituto de Investigaciones en Microbiología y Parasitología Médica, UBA, CONICET, Facultad de Medicina, Paraguay 2155 piso 13, C1121ABG Buenos \\ Aires, Argentina \\ ${ }^{\mathrm{b}}$ Laboratório de Imunologia e Inflamação, Departamento de Biologia Celular, Instituto de Biologia, Universidade de Brasília, Distrito Federal, Brazil \\ ${ }^{\mathrm{c}}$ Laboratório de Imunofarmacologia, Instituto Oswaldo Cruz-Fundaçao Oswaldo Cruz, Rio de Janeiro, Brazil
}

\section{A R T I C L E I N F O}

\section{Article history:}

Received 4 October 2015

Received in revised form 20 April 2016

Accepted 21 April 2016

\section{Keywords:}

Lipids

Babesia bovis

TLR6

Macrophages

\begin{abstract}
A B S T R A C T
Toll like receptors (TLRs) are involved in the modulation of diverse host genes expression through a complex network of signalling events that allow for an appropriate response to a microbial pathogen. In the present work we used TLR6KO mice in order to study the role of TLR6 in the immune discrimination of lipids from two Babesia bovis strains, attenuated R1A $\left(\mathrm{L}_{\mathrm{A}}\right)$ and virulent $\mathrm{S} 2 \mathrm{P}\left(\mathrm{L}_{V}\right)$, and the consequent macrophage activation. We demonstrated that TLR6 is required for lipid body induction in murine peritoneal macrophages by both $\mathrm{L}_{\mathrm{A}}$ and $\mathrm{L}_{\mathrm{V}}$. Interestingly, as regards IL- 10 and $\mathrm{COX}-2 / \mathrm{PGE}_{2}$ pathway induction by $\mathrm{L}_{\mathrm{A}}$ and $\mathrm{L}_{\mathrm{V}}$, we observed differences in the biological effects produced by these lipid extracts. Our results indicate a role of TLR6 in the down-modulation of these immunoregulators only in the case of $\mathrm{L}_{\mathrm{A}}$, whereas this receptor was not implicated in pro-inflammatory $\mathrm{TNF} \alpha$, IL- 6 and $\mathrm{KC}$ release induced by $\mathrm{L}_{\mathrm{A}}$. Remarkably, $\mathrm{L}_{\mathrm{V}}$ did not exert the down-modulatory effect observed for $\mathrm{L}_{\mathrm{A}}$, supporting the notion that $\mathrm{L}_{\mathrm{A}}$ and $\mathrm{L}_{V}$ possess different lipid composition that could correlate with the polar pathogenic effect of both $B$. bovis strains.
\end{abstract}

(C) 2016 Elsevier B.V. All rights reserved.

\section{Introduction}

Babesia bovis, prevalent in tropical and subtropical areas worldwide, is a tick transmitted intraerythrocytic apicomplexan protozoa responsible for bovine babesiosis. This haemoparasite causes severe haemolytic anaemia, abortion, cerebral dysfunction and death in susceptible animals and remains as an important constraint for the development of cattle industries (Bock et al., 2004).

Innate immune mechanisms represent the first line of defence against infectious agents and contribute significantly to the establishment of adaptive immunity. In $B$. bovis, the mechanism of protective immunity is postulated to involve both CD4-T-helper

Abbreviations: WT, wild type; TLR6KO, toll like receptor 6 knockout; $\mathrm{L}_{\mathrm{A}}$, total lipids of $B$. bovis attenuated strain; $\mathrm{L}_{V}$, total lipids of $B$. bovis virulent strain; COX-2, cyclooxygenase; $\mathrm{PGE}_{2}$, prostaglandin $\mathrm{E}_{2}$.

* Corresponding author at: Instituto de Investigaciones en Microbiología y Parasitología Médica, Universidad de Buenos Aires UBA, CONICET, Facultad de Medicina, Paraguay 2155 piso 13, C1121ABG Buenos Aires, Argentina.

E-mail address: paradife@fmed.uba.ar (G. Gimenez).
1 (Th1) lymphocyte and antibody responses (Norimine et al., 2003). In this sense, it has been reported that innate immune molecules derived from activated macrophages, such as nitric oxide and inflammatory cytokines, contribute to the limitation of acute babesiosis (Shoda et al., 2000 and Brown, 2001).

Toll-like receptors (TLRs) are important pattern recognition cell receptors that play a key role in the initial activation of the immune system and are able to identify a wide range of microbial components. Different members of the TLR family have been implicated in the interaction with molecules that possess a lipid component from a broad spectrum of organisms (Akira, 2003). As concerns TLR6 in particular, it is well known that this receptor can form a heterodimer with TLR2 for the recognition of diacyl lipopeptides, zymosan and lipoteichoic acid (Ozinsky et al., 2000); though, other authors have reported that during Mycobacterium leprae-Schwann cells interactions TLR6 has a critical role independent of its association with TLR2 (Mattos et al., 2011). It was also demonstrated that oxidized low-density lipoproteins trigger inflammatory signalling through the heterodimer TLR4-TLR6 (Stewart et al., 2010). In bovines, it has been reported that TLR6 is expressed in antigen 
presenting cells and possesses $74-84 \%$ nucleotide identity with respect to mouse/human sequences (Werling et al., 2006).

It is known that lipids from microorganisms have an important modulatory role in the immune system (Quesniaux et al., 2004). As regards $B$. bovis, it has been previously reported that naive cattle vaccinated with a chloroform extract from $B$. bovis-infected erythrocytes developed delayed and decreased parasitemias when challenged with a virulent strain of B. bovis (Goodger et al., 1990). Besides, lipids from erythrocytes infected with $B$. bovis Mexican strain stimulated inducible nitric oxide synthase and nitric oxide production by bovine macrophages in the presence of IFN $\gamma$. At variance, lipids from uninfected bovine erythrocytes did not produce any effect regarding these pro-inflammatory parameters (Shoda et al., 2000). In our laboratory, we demonstrated quantitative differences in the lipid composition of two $B$. bovis strains with polar pathogenic effect, attenuated R1A and virulent S2P (Gimenez et al., 2010). Moreover, we determined a differential effect of total lipids from R1A $\left(\mathrm{L}_{\mathrm{A}}\right)$ and S2P $\left(\mathrm{L}_{V}\right)$ : $\mathrm{L}_{\mathrm{A}}$ induced a strong activation of bovine macrophages, whereas $\mathrm{L}_{V}$ did not (Gimenez et al., 2012). In addition, similar results were obtained using murine peritoneal macrophages, although mice are not natural hosts of $B$. bovis. Besides, we demonstrated the involvement of TLR2 in the secretion of pro-inflammatory TNF $\alpha$, IL-6 and keratinocyte chemokine (KC) but only in the case of murine macrophages stimulated with $\mathrm{L}_{\mathrm{A}}$ (Gimenez et al., 2010). Noteworthy, R1A and S2P are polymorphic and do not constitute a "pair of strains", since the attenuated does not derive from the virulent one; nevertheless they have been well characterized as regards their biological behaviour (Guillemi et al., 2013 and Baravalle et al., 2012).

Lipid bodies, multifunctional organelles with key functions in lipid storage and cell signalling in different cell types, are critical regulators of different inflammatory and infectious diseases and markers of leukocyte activation. It has been reported that the increase of lipid bodies during infections correlates with eicosanoid generation through eicosanoid-forming enzymes like COX-2 among others (Bozza et al., 2011). This is a regulatory enzyme in the production of prostaglandin $\mathrm{E}_{2}\left(\mathrm{PGE}_{2}\right)$, a potent immunomodulator that down-regulates Th1 responses (Mattos et al., 2011). In relation to B. bovis, we demonstrated that only $\mathrm{L}_{A}$ induced a significant activation of murine macrophages with lipid body formation and COX-2 expression via TLR2 (Gimenez et al., 2010).

To extend our previous studies regarding B. bovis lipids-TLR2 interaction, herein we analysed the involvement of TLR6 in the murine macrophage inflammatory response induced by total lipids from B. bovis R1A and S2P strains. With this aim, we studied the induction of cytokines, chemokine and lipid body formation as well as COX-2 expression and $\mathrm{PGE}_{2}$ release in TLR6 knockout and wild type murine macrophages stimulated with both total lipids, $\mathrm{L}_{\mathrm{A}}$ and LV.

\section{Materials and methods}

\subsection{Reagents and antibodies}

Lipid standards, LPS from Escherichia coli (serotype 0127:b8) and peroxidase labelled (HRP) rabbit polyclonal anti goat IgG, were obtained from Sigma-Aldrich Co. (St. Louis, MO, USA). Organic solvents and osmium tetroxide were from Merck (Darmstadt, Germany). Nitrocellulose membrane and auto radiographic films were from GE Healthcare. TNF $\alpha$, IL-10, KC and $\mathrm{PGE}_{2}$ enzyme immunoassay kits were from Cayman Chemical (Ann Arbor, Michigan, USA). IL-6 enzyme-linked immunoassay kit was from R\&D Systems (Minneapolis, MN, USA). Rabbit polyclonal anti mouse $\beta$ actin and peroxidase labelled (HRP) goat anti rabbit IgG and goat polyclonal anti mouse COX-2 antibodies were from Santa Cruz Biotechnology Inc (Santa Cruz, CA, USA). Supersignal ${ }^{\circledR}$ West Pico chemiluminescent substrate was purchased from Pierce (Rockford, IL, USA).

\subsection{Parasites}

Merozoites from two polymorphic strains of $B$. bovis were used: R1A, attenuated and S2P, virulent (Guillemi et al., 2013). R1A is a vaccinal strain derived from an isolate responsible of a babesiosis outbreak in Santa Fe, Argentina, and attenuated after several passages through splenectomised calves (Anziani et al., 1993). S2P strain was isolated from a bovine during a babesiosis outbreak in Salta, Argentina (Mangold et al., 1993). Continuous in vitro multiplication does not modify the attenuated or virulent phenotypes of these strains (Baravalle et al., 2012). Parasites from both of them were cultured in bovine erythrocytes under microaerophilic conditions with medium replacement every $24 \mathrm{~h}$ and were harvested after 15 days of culture (50-60\% of parasitized erythrocytes for each strain) (Baravalle et al., 2012). Cultures were left overnight at $4{ }^{\circ} \mathrm{C}$ to favour merozoite release to the extracellular media and then centrifuged at $400 \mathrm{~g}$ for $10 \mathrm{~min}$ at $4{ }^{\circ} \mathrm{C}$. Merozoites present in the resulting supernatants were separated by centrifugation at $12,800 \mathrm{~g}$ for $20 \mathrm{~min}$ at $4{ }^{\circ} \mathrm{C}$ and stored at $-20^{\circ} \mathrm{C}$ until used for lipid extraction.

\subsection{Animals}

C57BL/6 mice were obtained from the Fundação Oswaldo Cruz breeding unit (RJ, Brazil). TLR6 knockout (TLR6KO) mice in a homogeneous C57BL/6 background (Takeuchi et al., 1999) were kindly donated by Dr. Shizuo Akira (Osaka University, Japan). Animals were maintained under standard conditions with free access to food and water in a room at $22-24^{\circ} \mathrm{C}$ and a $12 \mathrm{~h} \mathrm{light/dark} \mathrm{cycle}$ until used. All protocols were approved by the Fundaçao Oswaldo Cruz welfare committee.

\subsection{Preparation of total lipid extracts from $R 1 A\left(L_{A}\right)$ and $\operatorname{S2P}\left(L_{V}\right)$ B. bovis merozoites}

Lipids from different independent batches of R1A $\left(\mathrm{L}_{\mathrm{A}}\right)$ and S2P $\left(\mathrm{L}_{\mathrm{V}}\right)$ B. bovis merozoites and harvested from independent cultures, were prepared as previously described (Gimenez et al., 2010).

\subsection{Stimulation of TLR6KO and WT murine macrophages with $L_{A}$ or $L_{V}$}

Macrophages from TLR6KO and WT mice, obtained as described by Gimenez et al. (2010), were stimulated with independent batches of ethanol suspensions of $50 \mu \mathrm{g} / \mathrm{ml} \mathrm{L}_{\mathrm{A}}$ or $\mathrm{L}_{V}$, for $24 \mathrm{~h}$ at $37{ }^{\circ} \mathrm{C}$ in $5 \% \mathrm{CO}_{2}$. For negative control, cells were incubated with culture medium + vehicle $(0.5 \%$ ethanol). To show that TLR6KO macrophages remained functional they were stimulated with $1.5 \mathrm{ng} / \mathrm{ml}$ LPS, since this compound is a TLR4 ligand.

\subsection{Lipid body staining and counting}

Slides from TLR6KO or WT macrophages previously stimulated with $\mathrm{L}_{\mathrm{A}}$ or $\mathrm{L}_{V}$, while still moist, were stained and counted according to D'Avila et al. (2011). Images were obtained using CoolSNAPPro CF digital camera with Image-Pro Plus version 4.5.1.3 software (Media Cybernetics).

\subsection{COX-2 expression}

For COX-2 immunoblot analysis, WT and TLR6KO macrophages previously stimulated with $\mathrm{L}_{\mathrm{A}}$ or $\mathrm{L}_{\mathrm{V}}$ were resuspended in Laemmliís 
sample buffer, boiled and stored at $-20^{\circ} \mathrm{C}$ until used. Protein samples were separated in $10 \%$ SDS-PAGE, transferred to nitrocellulose membranes and blocked with Tris buffered saline $+0.05 \%$ Tween $20+5 \%$ skimmed milk for $2 \mathrm{~h}$ at room temperature. Membranes were then incubated with goat IgG anti COX-2 (1:100, v/v) and developed with anti-goat IgG-HRP conjugate $(1: 5000, v / v)$ using the SuperSignal West Pico Chemiluminescent Substrate, according to the manufacturer's instructions. Images were acquired by autoradiography. For loading control, detection of $\beta$-actin was performed in the same membranes as previously reported (Gimenez et al., 2010). The COX-2 band intensity was quantified by densitometry using Gel-Pro ${ }^{\circledR}$ Analyzer 4.0 software and normalized to that of the corresponding $\beta$-actin band.

\section{8. $P G E_{2}$ measurement}

Competitive enzyme immunoassay was used to directly determine $\mathrm{PGE}_{2}$ levels in supernatants from TLR6KO and WT macrophages previously stimulated with $\mathrm{L}_{\mathrm{A}}$ or $\mathrm{L}_{\mathrm{V}}$, according to manufacturer's instructions (Cayman Chemical).

\subsection{Cytokine and chemokine analysis}

TNF $\alpha, K C$, IL- 6 and IL-10 levels were determined by ELISA in the supernatants from TLR6KO and WT macrophages previously stimulated with $\mathrm{L}_{\mathrm{A}}$ or $\mathrm{L}_{\mathrm{V}}$, according to manufacturer's instructions (Cayman Chemical, R\&D Systems).

\subsection{Statistical analysis}

Results were expressed as mean \pm SEM. To compare between groups, unpaired Students $t$-test was used and values of $\mathrm{p}<0.05$ were considered significant. Data were analysed with GraphPad Prism 4 software for Windows.

\section{Results}

\section{1. $L_{A}$ and $L_{V}$ induce lipid body formation through a TLR6 dependent pathway}

In a previous work we determined that $\mathrm{L}_{\mathrm{A}}$ and $\mathrm{L}_{\mathrm{V}}$ induced differential lipid body formation via TLR2 (Gimenez et al., 2010). Since TLR6 can dimerize with TLR2, we here analysed if the former could also be involved in this process. Results showed that the induction of lipid body formation by both $\mathrm{L}_{\mathrm{A}}$ and $\mathrm{L}_{V}$ was significantly inhibited in TLR6KO macrophages with respect to WT cells (Fig. 1), thus indicating a requisite role for TLR6 in $B$. bovis lipids recognition to induce lipid body formation.

\section{2. $L_{A}$ induces high COX-2 expression in TLR6KO macrophages}

Having demonstrated that $\mathrm{L}_{\mathrm{A}}$ and $\mathrm{L}_{V}$ induced lipid body formation via TLR6 and considering that these organelles contain eicosanoid-forming enzymes, we next investigated if TLR6 was also involved in COX-2 expression when cells were stimulated by $\mathrm{L}_{\mathrm{A}}$ or $\mathrm{L}_{\mathrm{V}}$. Results demonstrated that $\mathrm{L}_{\mathrm{A}}$ induced a higher COX-2 expression in TLR6KO macrophages vs. WT cells (Fig. 2A, lanes 5 and 6 ), whereas $L_{V}$ failed to produce this response in both TLR6KO macrophages and, as we previously reported, in WT cells (lanes 3 and 4) (Gimenez et al., 2010). The densitometric analysis of immunoblots shows a 1.34-fold higher increase of COX-2 levels in TLR6KO with respect to WT cells (Fig. 2B).

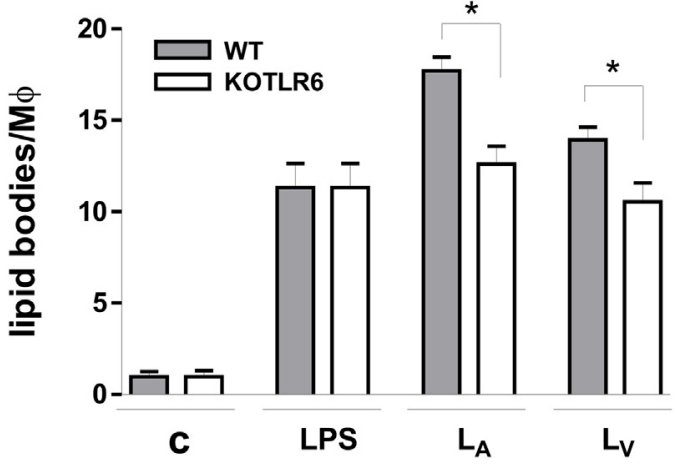

Fig. 1. $L_{A}$ and $L_{V}$ induce lipid body formation through a TLR6 dependent pathway. WT and TLR6KO macrophages were stimulated with independent batches of $\mathrm{L}_{\mathrm{A}}$ or $\mathrm{L}_{V}(50 \mu \mathrm{g} / \mathrm{ml}) 24 \mathrm{~h}$ at $37^{\circ} \mathrm{C}$. For controls, cells were incubated with vehicle $(0.5 \%$ ethanol, negative control) or LPS $(1.5 \mathrm{ng} / \mathrm{ml})$. Lipid bodies were visualized and enumerated after osmium staining. Each bar represents the mean \pm SEM from 50 consecutively counted macrophages of three independent pools (ten animals each). WT: wild type, TLR6KO: toll like receptor 6 knockout, $\mathrm{L}_{\mathrm{A}}$ : total lipids of $B$. bovis attenuated strain, $\mathrm{L}_{\mathrm{V}}$ : total lipids of $B$. bovis virulent strain, $C$ : negative control. ${ }^{*}$ Statistically significant ( $\mathrm{p} 0.05$ ).
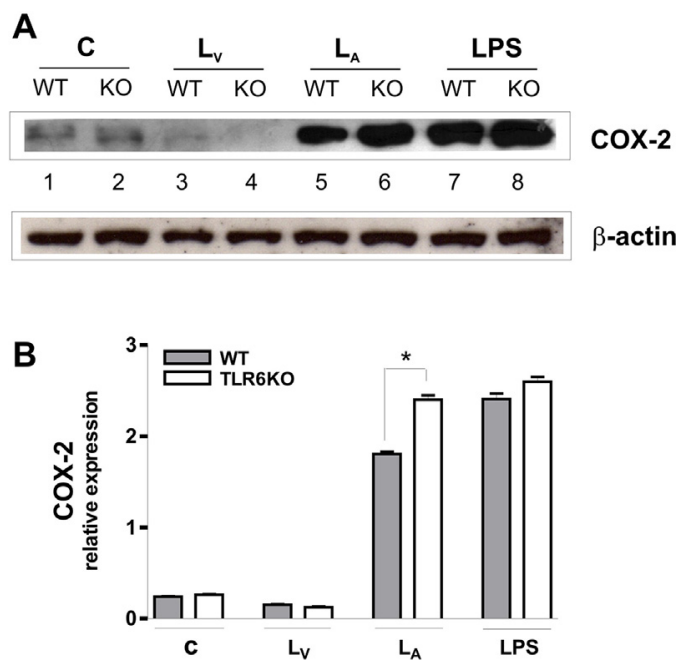

Fig. 2. $\mathrm{L}_{\mathrm{A}}$ induces high COX-2 expression in TLR6KO macrophages. Immunoblot analysis of COX-2 induction of WT and TLR6KO macrophages after stimulation with independent batches of $\mathrm{L}_{\mathrm{A}}$ or $\mathrm{L}_{V}(50 \mu \mathrm{g} / \mathrm{ml}), 24 \mathrm{~h}$ at $37^{\circ} \mathrm{C}$. For controls, cells were incubated with vehicle ( $0.5 \%$ ethanol, negative control) or LPS $(1.5 \mathrm{ng} / \mathrm{ml})$. Blots were reproved for $\beta$-actin as loading control. Blots are representative of three independent assays from three independent pools (ten animals each).

The intensity of the bands corresponding to $\mathrm{COX}-2$ were quantified by densitometry using Gel-Pro ${ }^{\circledR}$ Analyzer 4.0 software and normalized to the intensity of the corresponding $\beta$-actin band (loading control). Results are mean \pm SD of duplicate determinations from three independent immunoblot assays.

WT: wild type, KO and TLR6KO: toll like receptor 6 knockout, C: negative control, $\mathrm{L}_{\mathrm{A}}$ : total lipids of $B$. bovis attenuated strain, $\mathrm{L}_{\mathrm{V}}$ : total lipids of $B$. bovis virulent strain. ${ }^{*}$ Statistically significant (p 0.05).

\section{3. $L_{A}$ induces high $P G E_{2}$ release in TLR6KO macrophages}

Next, we analysed the effect of $\mathrm{L}_{\mathrm{A}}$ and $\mathrm{L}_{V}$ in $\mathrm{PGE}_{2}$ release, one of the products of COX-2 pathway. As shown in Fig. 3, $\mathrm{L}_{\mathrm{A}}$ induced in TLR6KO cells significantly higher levels of $\mathrm{PGE}_{2}$ with respect to WT and control cells, whereas in the case of $\mathrm{L}_{V}$, no differences were observed in $\mathrm{PGE}_{2}$ levels in both TLR6KO and WT, with respect to the controls (Fig. 3). All these data correlate with the results obtained above for COX-2 expression. 


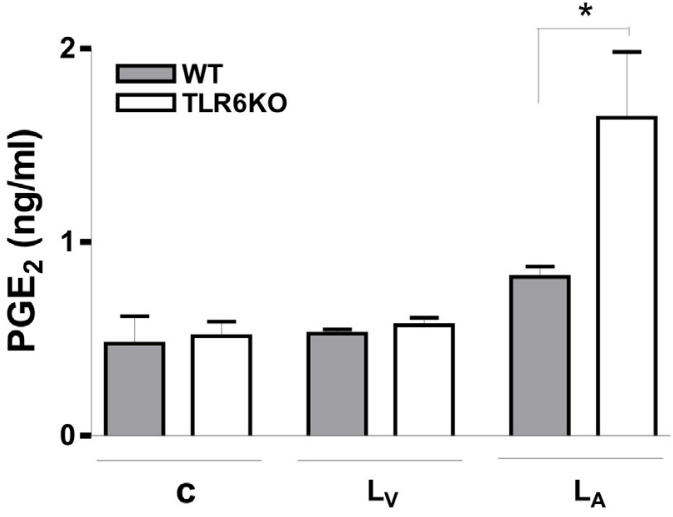

Fig. 3. $\mathrm{L}_{\mathrm{A}}$ induces high $\mathrm{PGE}_{2}$ release in TLR6KO macrophages.

PGE2 was determined by competitive enzyme immunoassay in the supernatants of WT and TLR6KO macrophages stimulated with independent batches of $\mathrm{L}_{\mathrm{A}}$ or $\mathrm{L}_{V}$ $(50 \mu \mathrm{g} / \mathrm{ml}), 24 \mathrm{~h}$ at $37^{\circ} \mathrm{C}$. Cells were incubated with vehicle $(0.5 \%$ ethanol) as negative control. Results represent the mean \pm SEM of triplicate assays from two independent pools (ten animals each).

WT: wild type, KO and TLR6KO: toll like receptor 6 knockout, C: negative control, $\mathrm{L}_{\mathrm{A}}$ : total lipids of $B$. bovis attenuated strain, $\mathrm{L}_{\mathrm{V}}$ : total lipids of $B$. bovis virulent strain. "Statistically significant ( $\mathrm{p} 0.05$ ).

\section{4. $L_{A}$ induces IL-10 release in TLR6KO macrophages}

Previously, we reported that $\mathrm{L}_{\mathrm{A}}$ produced a high release of proinflammatory cytokines TNF $\alpha$ and IL-6 as well as keratinocyte chemokine (KC), one of the major chemoattractants of neutrophils, in WT macrophages via TLR2 whereas $\mathrm{L}_{V}$ did not; besides, neither $\mathrm{L}_{\mathrm{A}}$ nor $\mathrm{L}_{\mathrm{V}}$ induced anti-inflammatory IL-10 secretion in WT and TLR2KO cells (Gimenez et al., 2010).

To study if TLR6 was involved in the production of these cytokines and chemokine induced by $\mathrm{L}_{A}$ or $\mathrm{L}_{V}$, we here determined these compounds in the supernatants of TLR6KO and WT cells treated with these lipids. As shown in Fig. 4, TNF $\alpha$, IL-6 and $\mathrm{KC}$ release was similar in both TLR6KO and WT macrophages when stimulated with $\mathrm{L}_{\mathrm{A}}$ or $\mathrm{L}_{\mathrm{V}}$ (Fig. $4 \mathrm{~A}-\mathrm{C}$ ), suggesting that TLR6 is not involved in the release of these factors induced by these lipids.

As regards $I L-10$, only $L_{A}$ induced significantly higher levels of this cytokine in TLR6KO with respect to WT or control cells (Fig. 4D); in contrast, no significant effect in this cytokine release was observed in TLR6KO cells vs WT and control cells when stimulated with $\mathrm{L}_{\mathrm{V}}$.

\section{Discussion}

Macrophages initiate the innate immune response by recognizing pathogens and inducing lipid body formation as well as lipid mediators and cytokine release. In this concern, TLRs present on their cell surface have been shown to participate in the recognition of a variety of microbial products (Akira, 2003). Herein we demonstrated that TLR6 was involved in the induction of lipid bodies, markers of inflammatory leukocytes, when murine macrophages were stimulated by the total lipids of both $B$. bovis strains, $\mathrm{L}_{\mathrm{A}}$ and $\mathrm{L}_{V}$. In a previous work we also established the implication of TLR2 in lipid body biogenesis induced by $\mathrm{L}_{\mathrm{A}}$ and $\mathrm{L}_{\mathrm{V}}$ (Gimenez et al., 2010), thus we propose that both lipids could be exerting this effect through TLR2-TLR6 heterodimers.

Lipid bodies are specialized intracellular domains that compartmentalize eicosanoid forming enzymes like COX-2, key enzyme that catalyses the rate-limiting step in the inducible production of prostaglandins such as $\mathrm{PGE}_{2}$. This prostanoid interferes with $\mathrm{T}$ lymphocyte responses and has an immunosuppressive effect in the context of several infections, favouring intracellular microorganism growth (Bozza et al., 2011 and D'Avila et al., 2011). The present finding that $\mathrm{L}_{\mathrm{A}}$ induced a higher increase of COX-2 expression and $\mathrm{PGE}_{2}$ release in TLR6KO than in WT cells, leads us to consider that TLR6 could have an inhibitory role in the formerly described up-regulation of this pathway induced via TLR2 by $\mathrm{L}_{\mathrm{A}}$ (Gimenez et al., 2010). We cannot rule out that the absence of TLR6 could be favouring TLR2 dimerization with other receptors, resulting in the up-regulation of this pathway in TLR6KO cells. Therefore, we propose that in WT macrophages TLR6 could have a direct or indirect down-modulatory effect on the inflammatory response induced by the interaction of $\mathrm{L}_{\mathrm{A}}$ with TLR2 and/or other receptors. Noteworthy, the present result showing TLR6 involvement in the down-modulation of $\mathrm{COX}-2 / \mathrm{PGE}_{2}$ pathway is not in line with those obtained for lipid body biogenesis stimulated by $\mathrm{L}_{\mathrm{A}}$. As lipid bodies are multifunctional organelles, additional pathways might be simultaneously operative upon $\mathrm{L}_{\mathrm{A}}$ stimulation. On the other hand, the fact that $\mathrm{L}_{V}$ did not induce COX-2/PGE 2 pathway in TLR6KO macrophages as well as in WT/TLR2KO cells as we previously reported, suggests us that the quantitative differences in the lipid composition of both $B$. bovis strains formerly determined, could account for their biological effects (Gimenez et al., 2010).

IL-10 avoids excessive activation of the immune response and limits immune pathology, but alternatively may prevent the complete eradication of pathogens (Arcanjo et al., 2015). The present data regarding IL-10 release in KOTLR6 macrophages induced by $\mathrm{L}_{\mathrm{A}}$, together with our earlier report that these lipids did not induce this cytokine in WT/TLR2KO cells (Gimenez et al., 2010), refer us again to the two possibilities previously raised in relation to COX-2/PGE 2 pathway: that TLR6 could be down-modulating IL10 production in WT cells when interacting with $\mathrm{L}_{\mathrm{A}}$ or that its absence could be favouring lipid interaction with other receptors, thus resulting in IL-10 release in TLR6KO cells. Additionally, the finding that $\mathrm{L}_{\mathrm{A}}$ induced a significantly high release of IL-10 in TLR6KO macrophages is consistent with the results obtained concerning COX-2 and $\mathrm{PGE}_{2}$, since the latter is known to be an important inducer of this cytokine (Arcanjo et al., 2015). Finally, the down-modulation of IL-10 induced by $\mathrm{L}_{\mathrm{A}}$ through TLR6 could result in the predominance of the pro-inflammatory phenotype already reported by our group (Gimenez et al., 2010). In contrast, TLR6 showed not to be implicated in pro-inflammatory TNF $\alpha$, IL-6 and $\mathrm{KC}$ release induced by $\mathrm{L}_{\mathrm{A}}$ in WT cells, marking a difference with our previous results regarding TLR2 involvement in these cytokines production (Gimenez et al., 2010). Besides, the present data that $\mathrm{L}_{V}$ did not exert effect in IL-10, TNF $\alpha$, IL-6 and KC release in KOTLR6 cells, supports once more the idea of a relationship between the differences in the lipid composition of $\mathrm{L}_{\mathrm{A}}$ and $\mathrm{L}_{\mathrm{V}}$ and the polar pathogenic effect of both $B$. bovis strains.

\section{Conclusions}

The data gathered in the present work reveal significant differences in the way murine macrophages respond to the lipids of the two $B$. bovis strains here analysed, pointing to a role for TLR6 in the down-modulation of the immunoregulators COX-2, $\mathrm{PGE}_{2}$ and IL-10 only induced by the lipids from the attenuated strain. Additional studies with a larger set of strains of polar phenotypes will provide a full understanding about the involvement of this receptor in the regulation of the immune response triggered by parasite lipids.

Even though live vaccines are efficient in preventing clinical cases of bovine babesiosis, they have significant disadvantages regarding safety, production and handling; thus there is great interest in the development of improved vaccination designs (Florin-Christensen et al., 2014). It has been proposed for some parasitic and viral diseases that multi-adjuvanted vaccines could simultaneously trigger several signalling pathways, eliciting robust 
A

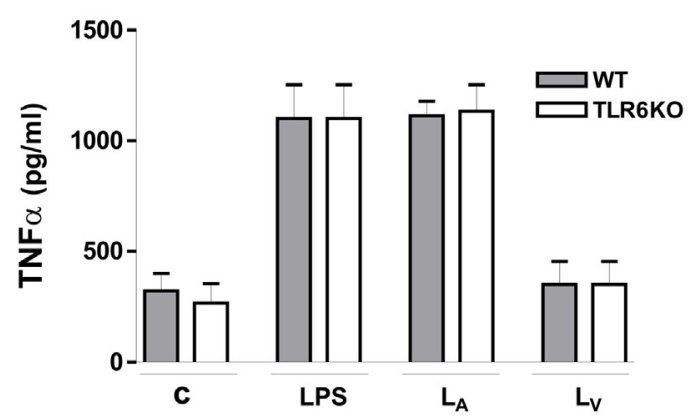

C

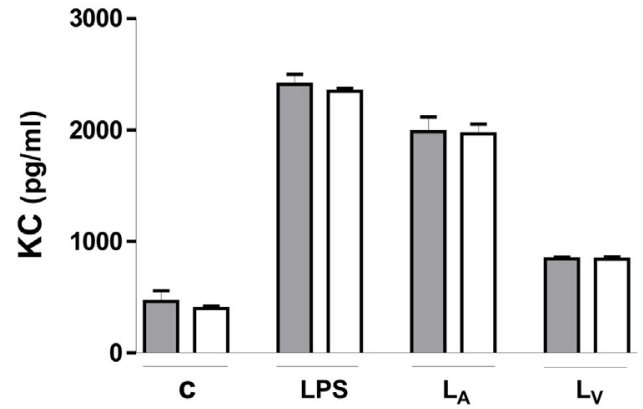

$\mathrm{B}$

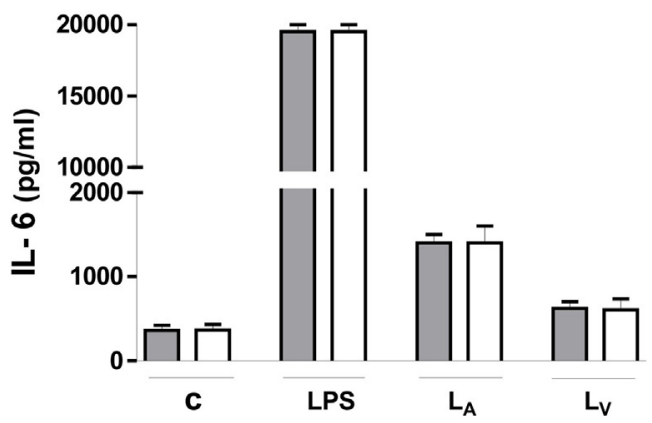

$\mathrm{D}$

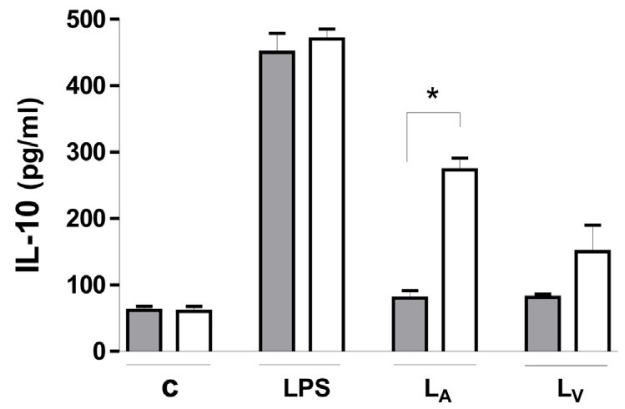

Fig. 4. $\mathrm{L}_{\mathrm{A}}$ induces IL-10 release in TLR6KO macrophages.

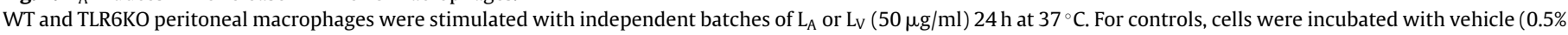

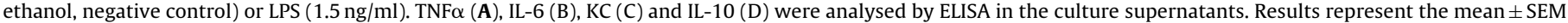
of triplicate assays from two independent pools (ten animals each).

WT: wild type, TLR6KO: toll like receptor 6 knockout, $\mathrm{L}_{\mathrm{A}}$ : total lipids of $B$. bovis attenuated strain, $\mathrm{L}_{V}$ : total lipids of $B$. bovis virulent strain, $\mathrm{C}$ : negative control.

*Statistically significant $(\mathrm{p}<0.05)$.

immune protection (Mount et al., 2013). Therefore, lipids from the attenuated R1A strain could be good candidates to be included in vaccine formulations as adjuvants in order to attain innovative immunoprophylactic strategies.

\section{Acknowledgements}

We are indebted to Dr. I. Echaide (Instituto Nacional de Tecnología Agropecuaria, Rafaela, Santa Fe, Argentina) for providing B. bovis cultures and to Dr. S. Akira (Department of Host Defense, Research Institute for Microbial Disease, Osaka, Japan) for providing the TLR6KO mice. This work was supported by Agencia Nacional de Promoción Científica y Tecnológica (FONCYT) and Consejo Nacional de Investigaciones Científicas y Técnicas (CONICET), Argentina and from Conselho Nacional de Desenvolvimento Científico e Tecnológico (CNPq) and Fundação de Amparo à Pesquisa do Estado do Rio de Janeiro (FAPERJ), Brazil.

\section{References}

-Akira, S., 2003. Toll-like receptor signalling. J. Biol. Chem. 278, 38105-38108. Anziani, O.S., Guglielmone, A.A., Abdala, A.A., Aguirre, D.H., Mangold, A.J., 1993. Protección conferida por Babesia bovis vacunal en novillos Holando Argentino. Rev. Med. Vet. 74, 47-49.

Arcanjo, A.F., LaRocque-de-Freitas, I.F., Rocha, J.D.B., Zamith, D., Costa-da-Silva, A.C., Pinheiro Nunes, M., Mesquita-Santos, F.P., Morrot, A., Filardy, A.A., Mariano, M., Bandeira-Melo, C., DosReis, G.A., Decote-Ricardo, D., Freire-de-Lima, C.G., 2015. The $\mathrm{PGE}_{2} / \mathrm{IL}-10$ axis determines susceptibility of B-1 cell-derived phagocytes (B-1CDP) to Leishmania major infection. PLoS One 10 (5), e0124888.

Baravalle, M.E., Thompson, C., Valentini, B., Ferreira, M., Torioni de Echaide, S., Florin-Christensen, M., Echaide, I., 2012. Babesia bovis biological clones and the inter-strain allelic diversity of the Bv80 gene support subpopulation selection as a mechanism involved in the attenuation of two virulent isolates. Vet. Parasitol. 190, 391-400.

Bock, R., Jackson, L., de Vos, A., Jorgensen, W., 2004. Babesiosis of cattle. Parasitology 129, S247-S269.

Bozza, P.T., Bakker-Abreu, I., Navarro-Xavier, R.A., Bandeira-Melo, C., 2011. Lipid body function in eicosanoid synthesis: an update. Prostaglandins Leukot. Essent. Fatty Acids 85, 205-213.

Brown, W.C., 2001. Molecular approaches to elucidating innate and acquired immune responses to Babesia bovis, a protozoan parasite that causes persistent infection. Vet. Parasitol. 101, 233-248.

D’Avila, H., Freire-de-Lima, C.G., Roque, N.R., Teixeira, L., Barja-Fidalgo, C., Silva, A.R., Melo, R.C., Dosreis, G.A., Castro-Faria-Neto, H.C., Bozza, P.T., 2011. Host cell lipid bodies triggered by Trypanosoma cruzi infection and enhanced by the uptake of apoptotic cells are associated with prostaglandin E2 generation and increased parasite growth. J. Infect. Dis. 204, 951-961.

Florin-Christensen, M., Suarez, C.E., Rodriguez, A.E., Flores, D.A., Schnittger, L., 2014. Vaccines against bovine babesiosis: where we are now and possible roads ahead. Parasitology 28, 1-30.

Gimenez, G., Magalhaes, K.G., Belaunzarán, M.L., Poncini, C.V., Lammel, E.M., González Cappa, S.M., Bozza, P.T., Isola, E.L., 2010. Lipids from attenuated and virulent Babesia bovis strains induce differential TLR2-mediated macrophage activation. Mol. Immunol. 47, 747-755.

Gimenez, G., Belaunzarán, M.L., Poncini, C.V., Blanco, F.C., Echaide, I., Zamorano, P., Lammel, E.M., González Cappa, S.M., Isola, E.L.D., 2012. Lipids from virulent S2P and attenuated R1A Babesia bovis strains trigger differential signaling and inflammatory responses in bovine macrophages. Parasitology 40, 530-540.

Goodger, B.V., Commins, M.A., Waltisbuhl, D.J., Wright, I.G., Rode-Bramanis, K., 1990. Babesia bovis: immunity induced by vaccination with a lipid enriched fraction. Int. J. Parasitol. 20, 685-687.

Guillemi, E., Ruybal, P., Lia, V., González, S., Farber, M., Wilkowsky, S.E., 2013. Multi-locus typing scheme for Babesia bovis and Babesia bigemina reveals high levels of genetic variability in strains from Northern Argentina. Infect. Genet. Evol. 14, 214-422.

Mangold, A.J., Aguirre, D.H., Cafrune, M.M., de Echaide, S.T., Guglielmone, A.A., 1993. Evaluation of the infectivity of a vaccinal and a pathogenic Babesia bovis strain from Argentina to Boophilus microplus. Vet. Parasitol. 51, 143-148.

Mattos, K.A., Oliveira, V.G., D’Avila, H., Rodrigues, L.S., Pinheiro, R.O., Sarno, E.N., Pessolani, M.C., Bozza, P.T., 2011. TLR6-driven lipid droplets in Mycobacterium 
leprae-infected Schwann cells: imunoinflammatory platforms associated with bacterial persistence. J. Immunol. 187, 2548-2558.

Mount, A., Koernig, S., Silva, A., Drane, D., Maraskovsky, E., Baz Morelli, A., 2013. Combination of adjuvants: the future of vaccine design. Expert Rev. Vaccines $12,733-746$.

Norimine, J., Mosqueda, J., Suarez, C., Palmer, G.H., McElwain, T.F., Mbassa, G., Brown, W.C., 2003. Stimulation of T-helper cell gamma interferon and immunoglobulin G responses specific for Babesia bovis rhoptry-associated protein 1 (RAP-1) or a RAP-1 protein lacking the carboxy-terminal repeat region is insufficient to provide protective immunity against virulent $B$. bovis challenge. Infect. Immun. 71, 5021-5032.

Ozinsky, A., Smith, K.D., Hume, D., Underhill, D.M., 2000. The repertoire for pattern recognition of pathogens by the innate immune system is defined by cooperation between toll-like receptors. Proc. Natl. Acad. Sci. U. S. A. 97, $13766-13771$.

Quesniaux, V.J., Nicolle, D.M., Torres, D., Kremer, L., Guérardel, Y., Nigou, J., Puzo, G., Erard, F., Ryffel, B., 2004. Toll-like receptor 2 (TLR2)-dependent-positive and TLR2-independent-negative regulation of proinflammatory cytokines by Mycobacterial Lipomannans. J. Immunol. 172, 4425-4434.
Shoda, L.K.M., Palmer, G.H., Florin-Christensen, J., Florin-Christensen, M., Godson, D.L., Brown, W.C., 2000. Babesia bovis-stimulated macrophages express interleukin-1, interleukin-12, tumor necrosis factor alpha, and nitric oxide and inhibit parasite replication in vitro. Infect. Immun. 68, 5139-5145.

Stewart, C.R., Stuart, L.M., Wilkinson, K., van Gils, J.M., Deng, J., Halle, A., Rayner, K.J., Boyer, L., Zhong, R., Frazier, W.A., Lacy-Hulbert, A., El Khoury, J., Golenbock, D.T., Moore, K.J., 2010. CD36 ligands promote sterile inflammation through assembly of a Toll-like receptor 4 and 6 heterodimer. Nat. Immunol. 22, $155-161$.

Takeuchi, O., Hoshino, K., Kawai, T., Sanio, H., Takada, H., Ogawa, T., Takeda, K., Akira, S., 1999. Differential roles of TLR2 and TLR4 in recognition of gram-negative and gram-positive bacterial cell wall components. Immunity $11,443-451$.

Werling, D., Piercy, J., Coffey, T.J., 2006. Expression of Toll-like receptors (TLR) by bovine antigen-presenting cells-potencial role in pathogen discrimination. Vet. Immunol. Immunopathol. 112, 2-11. 